\title{
Pharmacological Pain Treatment in 2012 and 2017 Among Older People with Major Neurocognitive Disorder
}

\author{
Maria Gustafsson $^{1}$ (D) $\cdot$ Hugo Lövheim ${ }^{2} \cdot$ Maria Sjölander $^{1}$
}

Accepted: 13 September 2021 / Published online: 19 October 2021

(c) The Author(s) 2021

\begin{abstract}
Background and Objective Pain is highly prevalent among older people, and treatment is complicated because of comorbidities and polypharmacy. Among people with major neurocognitive disorder additional difficulties might arise. The aim of this study was to describe analgesic drug use in 2012 and 2017 and associated factors among older people with major neurocognitive disorder.

Methods In this register-based study, the Swedish Dementia Registry and the Swedish Prescribed Drug Register were combined in order to obtain data regarding analgesic drug use among older people with major neurocognitive disorder. One or more filled prescriptions during the timeframe of 6 months (1 July-31 December 2012 and 1 July-31 December 2017) defined drug use during the respective period. A comparison between 2012 and 2017 was made, including a total of 56,101 people (20,889 and 35,212 respectively) with a mean age of 81.9 and 82.7 years, respectively.

Results The overall use of analgesic drugs increased significantly from $41.6 \%$ of individuals to $46.0 \%$ between the years 2012 and 2017. Users of opioid analgesics (15.2\% vs $17.3 \%)$ and paracetamol (37.0\% vs $42.3 \%)$ increased, while the users of non-steroidal anti-inflammatory drugs $(4.9 \%$ vs $2.7 \%)$ declined between the two data collections. Multiple logistic regression analyses were performed for different drugs and drug classes, and it was found that the use of opioids and paracetamol was associated with older age and a longer time since diagnosis. In contrast, non-steroidal anti-inflammatory drugs were associated with younger age and a shorter time since diagnosis.

Conclusions The results indicate that on a population level, pharmacological drug treatment has changed in line with guidelines between 2012 and 2017, with an increase in paracetamol and strong opioids and a decrease in non-steroidal antiinflammatory drugs and tramadol. The relatively high prevalence of opioids warrants concern given the significant risk of adverse effects among older people with major neurocognitive disorder.
\end{abstract}

\section{Key Points}

Pharmacological pain treatment was common among older people with major neurocognitive disorder in both 2012 and 2017.

The use of strong opioids to treat pain reflects guidelines, but the rather high prevalence found among older people in this study raises concern.

Maria Gustafsson

maria.gustafsson@umu.se

1 Department of Integrative Medical Biology, Umeå University, Umeå, Sweden

2 Department of Community Medicine and Rehabilitation, Umeå University, Umeå, Sweden

\section{Introduction}

Pain is a common condition among older people. Between 25 and $93 \%$ of older people report chronic pain, where the higher percentages refer to people living in nursing homes [1]. Chronic pain in older people has been found to impair quality of life and to increase sleep disturbances [2, 3]. In addition, common conditions among older people such as depression and immobility are associated with the occurrence of pain $[4,5]$.

Treating pain among older people is complicated because of comorbidities and polypharmacy [6, 7], and among people with major neurocognitive disorder (NCD) additional difficulties might arise. Because of the modified expression of pain [8] and limitations in the ability to communicate, the risk of inadequate treatment among older people with major NCD is high [9, 10]. Nevertheless, assessment of pain and pain treatment among people with major NCD is essential, 
as undiagnosed and inadequate pain treatment has been associated with increased use of healthcare services [11] and with neuropsychiatric symptoms such as aggression among this group of people [12].

Hip and knee osteoarthritis and vertebral compression are mainly nociceptive pain conditions common among older people [13, 14]. Pharmacological treatment regarding this type of pain includes opioids, paracetamol, and non-steroidal anti-inflammatory drugs (NSAIDs). Because of age-associated physiological changes such as changes in metabolism and elimination of drugs, as well as altered sensitivity to drugs, changes in the effects of drugs might occur. These changes increase the risk of adverse effects, and analgesic drugs such as NSAIDs have been associated with gastrointestinal bleeding, acute renal failure, and heart failure [15, 16], and opioids have been linked to falls, sedation, and cognitive impairment $[17,18]$, especially in the treatment of older people. The use of analgesic drugs is extensive among older people in Sweden, and these are among the most frequently used drug classes among people aged 75 years or older with polypharmacy [19]. Opioids and other analgesic drugs are also frequently prescribed in nursing homes, where a majority have cognitive impairment [20].

We used the Swedish Dementia Registry (SveDem) to collect data regarding registered people with major NCD. This registry started in 2007, and by the end of 2019 more than 89,000 people were registered [21]. Through record linkage with the Swedish Prescribed Drug Register, we obtained information regarding analgesic drug use in a large population of people with major NCD. The aim of this study was therefore to describe analgesic drug use in 2012 and 2017 and associated factors among older people with major NCD.

\section{Methods}

\subsection{Study Population}

In this register-based study, the SveDem and the Swedish Prescribed Drug Register were combined. Included in the study were people aged $\geq 65$ years and registered in SveDem. The Swedish Cause of Death Register was used to select people who were alive in the respective time periods. Two cross-sectional samples were collected from the dataset, one with people with diagnosis dates no later than 30 June, 2012 and alive on 31 December, $2012(n=20,889)$, and one with people with diagnosis dates no later than 30 June, 2017 and alive on 31 December, $2017(n=35,212)$. Data regarding filled prescriptions for analgesic drugs were collected for the periods 1 July-31 December 2012 and 1 July-31 December 2017.

\subsection{Definitions}

One or more filled prescriptions during the timeframe of 6 months (1 July-31 December 2012 and 1 July-31 December 2017) defined drug use during the respective period. Analgesics were classified according to the Anatomical Therapeutic Chemical Classification System as analgesic drugs (N02 + M01A), with the subgroups of opioid analgesics (N02A); paracetamol (N02BE); and NSAIDs (M01A). Glucosamine (M01AX05) was excluded from the NSAID (M01A) category. Migraine medications (N02C) were excluded from this study. In this study, strong opioids comprised morphine, oxycodone, ketobemidone, fentanyl, and tapentadol. In Sweden, buprenorphine is used in pain management almost exclusively as a low-dose transdermal patch formulation and is therefore not classified as a strong opioid in this study.

\subsection{Data Analysis}

Comparisons between 2012 and 2017 were made using the Chi-square test and t-test when appropriate. To analyze the associations between analgesic drugs and year, we applied a simple logistic regression analysis. To investigate associations between analgesic drugs and different factors, a multiple regression model was used. In this model, the following drugs and drug classes were analyzed: analgesic drugs (N02 + M01A), opioid analgesics (N02A), tramadol (N02AA01), paracetamol (N02BE); and NSAIDs (M01A). The model had the analgesic drug/drug class as the dependent variable and included the continuous variables age, years since diagnosis and baseline Mini-Mental State Examination (MMSE) score, and the categorical variables sex and year of investigation (2012 or 2017) as independent variables.

IBM SPSS Statistics version 26 and SAS Enterprise Guide 7.1 were used for all handling, calculations, and analyses of the data. We considered $p$ values $<0.05$ significant for all statistical tests, and odds ratios were calculated with 95\% confidence intervals.

\subsection{Ethics Approval}

The study was approved by the Regional Ethical Review Board in Umeå, Sweden (registration number 2017-256-31M).

\section{Results}

The characteristics of the samples are presented in Table 1 . There was a difference in age and years since diagnosis between the years 2012 and 2017, and in addition, there was a difference between the prevalence of different subtypes of 
major NCD, for example, Alzheimer's disease with early and late onset and vascular dementia.

Drug use in 2012 and 2017 is presented in Table 2. The overall use of analgesic drugs significantly increased from 41.6 to $46.0 \%$ of the individuals between the data collections $(p<0.001)$. Opioid analgesics increased from 15.2 to $17.3 \%$ $(p<0.001)$. The most commonly used opioid analgesic was oxycodone in both years. Strong opioids increased from 9.1 to $12.8 \%(p<0.001)$. Tramadol decreased significantly from 1.8 to $0.3 \%(p<0.001)$. Paracetamol increased from 37.0 to $42.3 \%(p<0.001)$ and the use of NSAIDs declined from 4.9 to $2.7 \%(p<0.001)$. Among NSAIDs, diclofenac was most commonly used in 2012, and ibuprofen was most commonly used in 2017. The number of people using both opioids and paracetamol was $2539(12.2 \%)$ in 2012 and $5048(14.3 \%)$ in $2017(p<0.001)$.

Multiple logistic regression analyses were performed for the following drugs and drug classes: analgesic drugs (N02 + M01A), opioid analgesics (N02A), tramadol (N02AA01), paracetamol (N02BE), and NSAIDs (M01A) (Table 3). Filled prescriptions for overall analgesic drugs were positively associated with year 2017 (compared to year 2012), female sex, older age, lower baseline MMSE, and a longer time since diagnosis.

Female sex was associated with the use of all subclasses and drugs, except tramadol. Older age and a longer time since diagnosis were associated with the use of opioids and paracetamol, while younger age and a shorter time since diagnosis were associated with tramadol and NSAIDs. The use of NSAIDs was associated with a higher MMSE score, while in contrast, the use of opioids and paracetamol was associated with a lower MMSE score.

The proportions of the total study population using analgesic drugs among different subtypes of major NCD are presented in Table 4. The use of overall analgesic drugs varied from $32.9 \%$ in AD with early onset to $50.1 \%$ in Parkinson's disease dementia. The use of all analgesic subgroups was lowest among people with AD with early onset except for tramadol and NSAIDs, where the use of NSAIDs was the highest of all subtypes of major NCD. The other Anatomical Therapeutic Chemical subgroups demonstrated less variation between different types of major NCD. The proportions of analgesics in different NCD subtypes in 2012 and 2017 separately are presented in the Supplementary Appendix (Tables A1 and A2).

\section{Discussion}

In this study, we found that the use of analgesic drugs increased from 42 to $46 \%$ between 2012 and 2017. This prevalence is lower than the prevalence of people using analgesic drugs in Swedish nursing homes in 2013 (66\%), and the prevalence found in Norwegian nursing homes in $2011(58 \%)[20,22]$. The fact that these studies were performed exclusively among people living in nursing homes, unlike the present study that includes both home-living and people living in nursing homes, might partly explain the differences. These studies also included both people with and without major NCD. There has been a concern that pain may be underdiagnosed in people with major NCD, and studies

Table 1 Basic characteristics of the studied samples

\begin{tabular}{llll}
\hline & 2012 & 2017 & $P$ value \\
\hline Total number of people, $n$ & 20,889 & 35,212 & $21,746 / 35,202(61.8)$ \\
Women, $n(\%)$ & $12,801 / 20,866(61.3)$ & $82.7 \pm 6.6$ & 0.254 \\
Age, mean \pm SD & $81.9 \pm 6.5$ & $683(1.9)$ & $<0.001$ \\
AD with early onset, $n(\%)$ & $477(2.3)$ & $11569(32.9)$ & 0.006 \\
AD with late onset, $n(\%)$ & $6438(30.8)$ & $6470(18.4)$ & $<0.001$ \\
Mixed AD and VaD, $n(\%)$ & $3728(17.8)$ & $6325(18.0)$ \\
VaD, $n(\%)$ & $3506(16.8)$ & $605(1.7)$ \\
DLB, $n(\%)$ & $392(1.9)$ & $444(1.3)$ & $445(1.3)$ \\
PDD, $n(\%)$ & $291(1.4)$ & $7796(22.1)$ & 0.117 \\
Frontotemporal dementia, $n(\%)$ & $247(1.2)$ & $875(2.5)$ & 0.170 \\
Unspecified, $n(\%)$ & $5356(25.6)$ & $3.0 \pm 2.2$ & 0.183 \\
Other dementia type, $n(\%)$ & $454(2.2)$ & $21.5 \pm 4.7$ & 0.399 \\
Years since diagnosis, mean \pm SD & $1.7 \pm 1.3$ & $<0.001$ \\
Baseline MMSE score, mean \pm SD & $21.5 \pm 4.9$ & 0.019 \\
\hline
\end{tabular}

$A D$ Alzheimer's disease, $D L B$ dementia with Lewy bodies, MMSE Mini-Mental State Examination, $P D D$ Parkinson's disease dementia, $S D$ standard deviation, $V a D$ vascular dementia

${ }^{a}$ Missing information in 1663 (2012) and 1590 (2017) cases 
Table 2 Analgesic drug use in 2012 and 2017

\begin{tabular}{|c|c|c|c|c|c|}
\hline & 2012 & 2017 & Odds ratio & $95 \%$ confidence interval & $P$ value \\
\hline All people, $n$ & 20,889 & 35,212 & & & \\
\hline Analgesic drugs (N02 + M01A), $n(\%)$ & 8695 (41.6) & $16,193(46.0)$ & 1.194 & $1.153-1.236$ & $<0.001$ \\
\hline Opioid analgesics (N02A), $n(\%)$ & $3165(15.2)$ & $6093(17.3)$ & 1.172 & $1.118-1.228$ & $<0.001$ \\
\hline Morphine & $826(4.0)$ & $1317(3.7)$ & & & \\
\hline Morphine with spasmolytics & $18(0.1)$ & $28(0.1)$ & & & \\
\hline Oxycodone & $877(4.2)$ & $2847(8.1)$ & & & \\
\hline Ketobemidone & $45(0.2)$ & $42(0.1)$ & & & \\
\hline Fentanyl & $380(1.8)$ & $689(2.0)$ & & & \\
\hline Tapentadol & $7(0.0)$ & $37(0.1)$ & & & \\
\hline Buprenorphine & $810(3.9)$ & $1695(4.8)$ & & & \\
\hline Codeine & $525(2.5)$ & $388(1.1)$ & & & \\
\hline Tramadol (N02AA01) & $367(1.8)$ & $114(0.3)$ & 0.182 & $0.147-0.224$ & $<0.001$ \\
\hline Paracetamol (N02BE), $n(\%)$ & $7732(37.0)$ & $14,898(42.3)$ & 1.248 & $1.205-1.293$ & $<0.001$ \\
\hline NSAID (M01A), $n(\%)$ & $1024(4.9)$ & $941(2.7)$ & 0.533 & $0.487-0.583$ & $<0.001$ \\
\hline Diclofenac & $379(1.8)$ & $145(0.4)$ & & & \\
\hline Ibuprofen & $253(1.2)$ & $243(0.7)$ & & & \\
\hline Naproxen & $264(1.3)$ & $383(1.1)$ & & & \\
\hline Ketoprofen & $42(0.2)$ & $38(0.1)$ & & & \\
\hline Dexibuprofen & $34(0.2)$ & $21(0.1)$ & & & \\
\hline Celecoxib & $25(0.1)$ & $23(0.1)$ & & & \\
\hline Etoricoxib & $50(0.2)$ & $99(0.3)$ & & & \\
\hline Nabumeton & $24(0.1)$ & $15(0.0)$ & & & \\
\hline
\end{tabular}

NSAID non-steroidal anti-inflammatory drug

Only drugs with a prevalence $\geq 0.1 \%$ are presented separately

performed further back in time show a generally lower use of analgesics in people with major NCD compared with those without [23-25]. However, other, more recent studies have found that people with major NCD were no less likely to receive analgesics compared to those without [20, $22,26]$. These results could indicate changed prescription patterns and a greater awareness of analgesic use in people with major NCD. It is not possible to draw any conclusions regarding inequality between people with and without major NCD based on the results in this study. Further, information about pain was not available in the registry, which means that we cannot draw any conclusions about the appropriateness of analgesic prescribing in the individual person. However, unlike many other studies, the present study includes a large population, including people with major NCD only. On a population level, it might therefore be possible to draw the conclusion that the increase in strong opioids and paracetamol, and the decrease in NSAIDs and tramadol reflect current recommendations for the treatment of the pain in fragile older people [18, 27].

The increase of opioids (with the exception of the weak opioid tramadol) found in this study is in accordance with previous studies that show a high prevalence of these drugs among people with major NCD $[26,28]$. The use of opioids to treat pain admittedly reflects guidelines among older people [27], but the rather high prevalence found in this study raises concern. Almost one in five in our study population were prescribed opioids, and in line with other studies, the use was associated with older age [26] and with a lower MMSE score and a longer time since diagnosis. Of note, opioids are associated with adverse reactions that increase with age, frailty, and major NCD [29]. Strong opioids comprised the majority of opioids used in our study, with the most prevalent being oxycodone both years. Buprenorphine, a partial agonist/antagonist, has become increasingly prescribed to people with major NCD [30], and in our study, $28 \%$ of those taking opioids were using this drug in 2017. Buprenorphine that is administered as a transdermal patch formulation might be an alternative in, for example, people with non-adherence or swallowing difficulties. Buprenorphine has been well tolerated in elderly patients in general, with a low risk of serious adverse events [31]. However, poor tolerability and an increased risk of psychiatric and neurological adverse events have been found among people with major NCD using buprenorphine [32]. These adverse events might be interpreted as neuropsychiatric symptoms and might not be recognized [33]. 
Table 3 Multiple logistic regression analysis of factors associated with different drugs/drug classes

\begin{tabular}{|c|c|c|c|}
\hline & Odds ratio & $\begin{array}{l}95 \% \text { confidence } \\
\text { interval }\end{array}$ & $P$ value \\
\hline \multicolumn{4}{|l|}{ Analgesic drugs } \\
\hline Year $2017^{a}$ & 1.057 & $1.017-1.098$ & 0.005 \\
\hline Female sex & 1.487 & $1.434-1.543$ & $<0.001$ \\
\hline Older age & 1.039 & $1.036-1.042$ & $<0.001$ \\
\hline MMSE $^{\mathrm{b}}$ & 0.970 & $0.966-0.973$ & $<0.001$ \\
\hline $\begin{array}{l}\text { Years since diag- } \\
\text { nosis }\end{array}$ & 1.091 & $1.081-1.101$ & $<0.001$ \\
\hline \multicolumn{4}{|l|}{ Opioid analgesics } \\
\hline Year $2017^{\mathrm{a}}$ & 1.053 & $1.000-1.110$ & 0.051 \\
\hline Female sex & 1.558 & $1.480-1.640$ & $<0.001$ \\
\hline Older age & 1.029 & $1.026-1.033$ & $<0.001$ \\
\hline $\mathrm{MMSE}^{\mathrm{b}}$ & 0.973 & $0.968-0.978$ & $<0.001$ \\
\hline $\begin{array}{l}\text { Years since diag- } \\
\text { nosis }\end{array}$ & 1.076 & $1.063-1.088$ & $<0.001$ \\
\hline \multicolumn{4}{|l|}{ Tramadol } \\
\hline Year $2017^{\mathrm{a}}$ & 0.211 & $0.168-0.265$ & $<0.001$ \\
\hline Female sex & 1.242 & $1.019-1.515$ & 0.032 \\
\hline Older age & 0.965 & $0.951-0.979$ & $<0.001$ \\
\hline $\mathrm{MMSE}^{\mathrm{b}}$ & 1.013 & $0.923-1.033$ & 0.223 \\
\hline $\begin{array}{l}\text { Years since diag- } \\
\text { nosis }\end{array}$ & 0.931 & $0.875-0.992$ & 0.026 \\
\hline \multicolumn{4}{|l|}{ Paracetamol } \\
\hline Year $2017^{\mathrm{a}}$ & 1.116 & $1.073-1.161$ & $<0.001$ \\
\hline Female sex & 1.471 & $1.417-1.527$ & $<0.001$ \\
\hline Older age & 1.045 & $1.042-1.048$ & $<0.001$ \\
\hline $\mathrm{MMSE}^{\mathrm{b}}$ & 0.970 & $0.966-0.973$ & $<0.001$ \\
\hline $\begin{array}{l}\text { Years since diag- } \\
\text { nosis }\end{array}$ & 1.078 & $1.068-1.088$ & $<0.001$ \\
\hline \multicolumn{4}{|l|}{ NSAID } \\
\hline Year $2017^{a}$ & 0.599 & $0.543-0.661$ & $<0.001$ \\
\hline Female sex & 1.236 & $1.121-1.364$ & $<0.001$ \\
\hline Older age & 0.953 & $0.946-0.960$ & $<0.001$ \\
\hline $\mathrm{MMSE}^{\mathrm{b}}$ & 1.043 & $1.032-1.054$ & $<0.001$ \\
\hline $\begin{array}{l}\text { Years since diag- } \\
\text { nosis }\end{array}$ & 0.946 & $0.921-0.972$ & $<0.001$ \\
\hline
\end{tabular}

MMSE Mini-Mental State Examination, NSAID non-steroidal antiinflammatory drugs

${ }^{a}$ Reference category year 2012

${ }^{\mathrm{b}}$ Data were missing for 3253 individuals

Another adverse reaction associated with opioids in general is constipation, and concomitant laxatives are not always prescribed [34]. This is of particular importance among people with major NCD who might have difficulty detecting and communicating problems such as constipation. In conclusion, prescribing opioids in people with major NCD should be based on a careful risk-benefit evaluation and followed by a continuous assessment of efficacy and side effects.

The increase and generally high prevalence of paracetamol found in this study is consistent with evidence and guidelines that suggest that paracetamol is effective and safe and is therefore proposed as a first-line therapy for pain relief in those with major NCD [35, 36]. It is important to be observant, however, of the increased risk of bleeding with concomitant treatment with warfarin (this applies to continuous treatment with paracetamol in doses above $2 \mathrm{~g} /$ day) [37]. The decrease in NSAIDs and tramadol from an already low level is in line with previous research [20] and is in accordance with guidelines [18, 27]. The association with an increased risk of potentially serious adverse events especially regarding NSAIDs is well known, and these medications should therefore be avoided [18, 38]. Of interest is the transition from diclofenac to naproxen and ibuprofen, which probably depends on the environmental issues concerning diclofenac [39]. Younger age, a shorter time since diagnosis, and higher MMSE were associated with the use of both NSAIDs and tramadol, which can be interpreted as physicians being restrictive in prescribing these drugs to fragile people.

The distribution of different analgesic drugs and drug classes among different major NCD subtypes is quite difficult to interpret. Research indicates that different NCD subtypes may experience pain differently [33]. People with Alzheimer's disease and vascular dementia seem to have an augmented vulnerability to pain [33], while people with frontotemporal dementia might have an increased pain threshold [40]. Although no pain diagnoses were available in our study, the prevalence of overall analgesic drugs and all drug classes were among the lowest in people with frontotemporal dementia compared with other NCD subtypes, and thus were in line with this reasoning.

One of the strengths of this study is that we used registrybased data, which means that we were able to investigate drug use among a well-defined large group of people with major NCD. In the study, we used data on filled prescriptions, which gives an overview of the use of analgesic drugs. However, we did not have any information about how the people used these medications, and we only considered if a prescription was filled according to our definition. Further, we did not have information of the prevalence of pain in the population, or if this changed between the years, which might have affected the need for pharmacological pain treatment. Another limitation in this study is that we were not able to distinguish between home-living people and people living in nursing homes, which complicates the comparisons with other studies. 
Table 4 Numbers and proportions of the total study population $(n=56101)$ who filled at least one prescription for analgesic drugs within different major NCD subtypes

\begin{tabular}{|c|c|c|c|c|c|}
\hline Major NCD subtype & $\begin{array}{l}\text { Analgesic drugs } \\
n(\%)\end{array}$ & $\begin{array}{l}\text { Opioid analgesics } \\
n(\%)\end{array}$ & $\begin{array}{l}\text { Tramadol } \\
n(\%)\end{array}$ & Paracetamol $n(\%)$ & $\begin{array}{l}\text { NSAID } \\
n(\%)\end{array}$ \\
\hline $\mathrm{AD}$ with early onset & $382(32.9)$ & $130(11.2)$ & $8(0.7)$ & $328(28.1)$ & $53(4.6)$ \\
\hline $\mathrm{AD}$ with late onset & $7285(40.5)$ & 2637 (14.6) & $130(0.7)$ & $6565(36.5)$ & $685(3.8)$ \\
\hline Mixed $\mathrm{AD}$ and $\mathrm{VaD}$ & $4603(45.1)$ & $1740(17.1)$ & $77(0.8)$ & $4198(41.2)$ & $336(3.3)$ \\
\hline $\mathrm{VaD}$ & $4753(48.3)$ & 1894 (19.3) & $120(1.2)$ & $4332(44.1)$ & $313(3.2)$ \\
\hline DLB & $474(47.5)$ & $140(14.0)$ & $5(0.5)$ & $444(44.5)$ & $35(3.5)$ \\
\hline PDD & $368(50.1)$ & $114(15.5)$ & $2(0.3)$ & $331(45.0)$ & $33(4.5)$ \\
\hline Frontotemporal dementia & $250(36.1)$ & $84(12.1)$ & $3(0.4)$ & $230(33.2)$ & $23(3.3)$ \\
\hline Unspecified & $6204(47.2)$ & $2308(17.5)$ & $120(0.9)$ & $5685(43.2)$ & $437(3.3)$ \\
\hline Other dementia type & $569(42.8)$ & $211(15.9)$ & $16(1.2)$ & $519(39.1)$ & $50(3.8)$ \\
\hline
\end{tabular}

$A D$ Alzheimer's disease, $D L B$ dementia with Lewy bodies, $N C D$ neurocognitive disorder, $P D D$ Parkinson's disease dementia, VaD vascular dementia

\section{Conclusions}

The results indicate that on a population level, pharmacological drug treatment has changed in line with guidelines between 2012 and 2017, with an increase in paracetamol and strong opioids and a decrease in NSAIDs and tramadol. The relatively high prevalence of opioids warrants concern given the significant risk of adverse effects among older people with major NCD.

Supplementary Information The online version contains supplementary material available at https://doi.org/10.1007/s40266-021-00897-9.

Acknowledgements The Swedish Dementia Registry provided data on patients with dementia.

\section{Declarations}

Funding Open access funding was provided by Umea University. The Swedish Dementia Association provided funding for the preparation of this article.

Conflict of interest The authors declare that they have no conflicts of interest.

Ethics approval The study was approved by the Regional Ethical Review Board in Umeå, Sweden (Registration Number 2017-256$31 \mathrm{M})$.

\section{Consent to participate Not applicable.}

Consent for publication Not applicable.

Availability of data and material The datasets generated during and/ or analysed in the present study are available from the corresponding author on reasonable request.

Code availability Not applicable.
Author contributions MG, HL, and MS analyzed and interpreted the data and prepared the manuscript. MG and MS were responsible for the study concept, design, and acquisition of subjects. All authors discussed the results and contributed to the manuscript and approved the final version.

Open Access This article is licensed under a Creative Commons Attribution-NonCommercial 4.0 International License, which permits any non-commercial use, sharing, adaptation, distribution and reproduction in any medium or format, as long as you give appropriate credit to the original author(s) and the source, provide a link to the Creative Commons licence, and indicate if changes were made. The images or other third party material in this article are included in the article's Creative Commons licence, unless indicated otherwise in a credit line to the material. If material is not included in the article's Creative Commons licence and your intended use is not permitted by statutory regulation or exceeds the permitted use, you will need to obtain permission directly from the copyright holder. To view a copy of this licence, visit http://creativecommons.org/licenses/by-nc/4.0/.

\section{References}

1. Abdulla A, Adams N, Bone M, Elliott AM, Gaffin J, Jones D, et al. Guidance on the management of pain in older people. Age Ageing. 2013;42(1):1-57.

2. Pickering ME, Chapurlat R, Kocher L, Peter-Derex L. Sleep disturbances and osteoarthritis. Pain Pract. 2016;16(2):237-44.

3. Zanocchi M, Maero B, Nicola E, Martinelli E, Luppino A, Gonella $\mathrm{M}$, et al. Chronic pain in a sample of nursing home residents: prevalence, characteristics, influence on quality of life (QoL). Arch Gerontol Geriatr. 2008;47(1):121-8.

4. Reid MC, Williams CS, Gill TM. The relationship between psychological factors and disabling musculoskeletal pain in community-dwelling older persons. J Am Geriatr Soc. 2003;51(8):1092-8.

5. Shah RC, Buchman AS, Boyle PA, Leurgans SE, Wilson RS, Andersson GB, et al. Musculoskeletal pain is associated with incident mobility disability in community-dwelling elders. J Gerontol A Biol Sci Med Sci. 2011;66(1):82-8.

6. Fried LP, Ferrucci L, Darer J, Williamson JD, Anderson G. Untangling the concepts of disability, frailty, and comorbidity: 
implications for improved targeting and care. J Gerontol A Biol Sci Med Sci. 2004;59(3):M255-63.

7. Mallet L, Spinewine A, Huang A. The challenge of managing drug interactions in elderly people. Lancet. 2007;370(9582):185-91.

8. Corbett A, Huse Abo B, Malcangio M, Staniland A, Cohen-Mansfield J, Aarsland D, et al. Assessment and treatment of pain in people with dementia. Nat Rev Neurol. 2012;8(5):264-74.

9. Fain KM, Alexander GC, Dore DD, Segal JB, Zullo AR, CastilloSalgado C. Frequency and predictors of analgesic prescribing in U.S. nursing home residents with persistent pain. J Am Geriatr Soc. 2017;65(2):286-93.

10. de Souto BP, Lapeyre-Mestre M, Vellas B, Rolland Y. Potential underuse of analgesics for recognized pain in nursing home residents with dementia: a cross- sectional study. Pain. 2013;154(11):2427-31.

11. Kunik ME, Cully JA, Snow AL, Souchek J, Sullivan G, Ashton CM. Treatable comorbid conditions and use of VA health care services among patients with dementia. Psychiatr Serv. 2005;56(1):70-5.

12. Kunik ME, Snow AL, Davila JA, Steele AB, Balasubramanyam $\mathrm{V}$, Doody RS, et al. Causes of aggressive behavior in patients with dementia. J Clin Psychiatry. 2010;71(9):1145-52.

13. Cross M, Smith E, Hoy D, Nolte S, Ackerman I, Fransen M, et al. The global burden of hip and knee osteoarthritis: estimates from the Global Burden of Disease 2010 study. Ann Rheum Dis. 2014;73(7):1323-30.

14. Reid MC, Eccleston C, Pillemer K. Management of chronic pain in older adults. BMJ. 2015;350(2):h532.

15. Langman MJS, Weil J, Wainwright P, Lawson DH, Rawlins MD, Logan RFA, et al. Risks of bleeding peptic ulcer associated with individual non-steroidal anti-inflammatory drugs. Lancet. 1994;343(8905):1075-8.

16. Bleumink G, Feenstra J, Sturkenboom M, Stricker B. Nonsteroidal anti-inflammatory drugs and heart failure. Drugs. 2003;63(6):525-34.

17. Seppala LJ, van de Glind EMM, Daams JG, Ploegmakers KJ, de Vries M, Wermelink AMAT, et al. Fall-risk-increasing drugs: a systematic review and meta-analysis: III. Others. J Am Med Dir Assoc. 2018;19(4):372.e1-8.

18. The National Board of Health and Welfare. Indikatorer för god läkemedelsterapi hos äldre. Indicators for evaluating the quality of older people's drug therapy. 2017. https://www.socialstyrelsen.se/ Lists/Artikelkatalog/Attachments/20644/2017-6-7.pdf. Accessed 23 Sept 2021.

19. Wastesson JW, Cedazo Minguez A, Fastbom J, Maioli S, Johnell K. The composition of polypharmacy: a registerbased study of Swedes aged 75 years and older. PLoS ONE. 2018;13(3):e0194892.

20. Hemmingsson E-S, Gustafsson M, Isaksson U, Karlsson S, Gustafson Y, Sandman P-O, et al. Prevalence of pain and pharmacological pain treatment among old people in nursing homes in 2007 and 2013. Eur J Clin Pharmacol. 2018;74(4):483-8.

21. SveDem: Svenska Demensregistret. www.ucr.uu.se/svedem/. Accessed 23 Sept 2021.

22. Sandvik R, Selbaek G, Kirkevold O, Aarsland D, Husebo BS. Analgesic prescribing patterns in Norwegian nursing homes from 2000 to 2011: trend analyses of four data samples. Age Ageing. 2016;45(1):54-60.

23. Tan E, Jokanovic N, Koponen M, Thomas D, Hilmer S, Bell J. Prevalence of analgesic use and pain in people with and without dementia or cognitive impairment in aged care facilities: a systematic review and meta-analysis. Curr Clin Pharmacol. 2015;10(3):194-203.

24. Veal FC, Bereznicki LR, Thompson AJ, Peterson GM. Pharmacological management of pain in Australian aged care facilities. Age Ageing. 2014;43(6):851-6.
25. Hoffmann F, Van Den Bussche H, Wiese B, Glaeske G, Kaduszkiewicz H. Diagnoses indicating pain and analgesic drug prescription in patients with dementia: a comparison to age- and sex-matched controls. BMC Geriatr. 2014;14(1):20.

26. Jensen-Dahm C, Gasse C, Astrup A, Mortensen PB, Waldemar G. Frequent use of opioids in patients with dementia and nursing home residents: a study of the entire elderly population of Denmark. Alzheimers Dement. 2015;11(6):691-9.

27. American Geriatrics Society Panel on the Pharmacological Management of Persistent Pain in Older Persons. Pharmacological management of persistent pain in older persons. Pain Med. 2009;10(6):1062-83.

28. Sandvik RK, Selbaek G, Seifert R, Aarsland D, Ballard C, Corbett A, et al. Impact of a stepwise protocol for treating pain on pain intensity in nursing home patients with dementia: a cluster randomized trial. Eur J Pain. 2014;18(10):1490-500.

29. McLachlan AJ, Bath S, Naganathan V, Hilmer SN, Le Couteur DG, Gibson SJ, et al. Clinical pharmacology of analgesic medicines in older people: impact of frailty and cognitive impairment. Br J Clin Pharmacol. 2011;71(3):351-64.

30. Mörttinen-Vallius H, Hartikainen S, Seinelä L, Jämsen E. The prevalence of and exact indications for daily opioid use among aged home care clients with and without dementia. Aging Clin Exp Res. 2021;33(5):1239-47.

31. Pergolizzi J, Böger RH, Budd K, Dahan A, Erdine S, Hans $\mathrm{G}$, et al. Opioids and the management of chronic severe pain in the elderly: consensus statement of an international expert panel with focus on the six clinically most often used World Health Organization step III opioids (buprenorphine, fentanyl, hydromorphone, methadone, morphine, oxycodone). Pain Pract. 2008;8(4):287-313.

32. Erdal A, Flo E, Aarsland D, Ballard C, Slettebo DD, Husebo BS. Efficacy and safety of analgesic treatment for depression in people with advanced dementia: randomised, multicentre, doubleblind, placebo-controlled trial (DEP.PAIN.DEM). Drugs Aging. 2018;35(6):545-58.

33. Achterberg W, Lautenbacher S, Husebo B, Erdal A, Herr K. Pain in dementia. Pain Rep. 2020;5(1):e803.

34. Gustafsson $\mathrm{M}$, Lämås $\mathrm{K}$, Isaksson U, Sandman P-O, Lövheim $\mathrm{H}$. Constipation and laxative use among people living in nursing homes in 2007 and 2013. BMC Geriatr. 2019;19(1):38.

35. Erdal A, Ballard C, Vahia IV, Husebo BS. Analgesic treatments in people with dementia: how safe are they? A systematic review. Expert Opin Drug Saf. 2019;18(6):511-22.

36. Husebo BS, Achterberg W, Flo E. Identifying and managing pain in people with Alzheimer's disease and other types of dementia: a systematic review. CNS Drugs. 2016;30(6):481-97.

37. Janusinfo. Sfinx interaktionstjänst [SFINX interaction services]. Stockholm. Department of clinical pharmacology. Karolinska Institutet/Medication Centre SLL, Medbase Ltd. http://www.janus info.se/Beslutsstod/Interaktioner/Ny-version-av-Sfinx-interaktio nstjanst/. Accessed 23 Sept 2021.

38. American Geriatrics Society. 2019 updated AGS Beers Criteria for potentially inappropriate medication use in older adults. J Am Geriatr Soc. 2019;67:674-94.

39. Näslund J, Asker N, Fick J, Larsson DGJ, Norrgren L. Naproxen affects multiple organs in fish but is still an environmentally better alternative to diclofenac. Aquat Toxicol. 2020;227:105583.

40. Bathgate D, Snowden JS, Varma A, Blackshaw A, Neary D. Behaviour in frontotemporal dementia, Alzheimer's disease and vascular dementia: behaviour in frontotemporal dementia. Acta Neurol Scand. 2001;103(6):367-78. 